\title{
Ergonomic approach in a painting process of a electroplating company situated in the Industrial Pole of Manaus
}

\section{Hormino Mendes Contente Neto ${ }^{1}$, Jandecy Cabral Leite Junior ${ }^{2}$, Worlen Ferreira Gimack ${ }^{3}$}

${ }^{1,3}$ Laureate International Universities - UNINORTE - Av. Djalma Batista, 2100 - N. Sr ${ }^{\mathrm{a}}$. das Graças, Plaza Shopping. Manaus - AM.

${ }^{2}$ Instituto de Tecnologia e Educação Galileo da Amazônia (ITEGAM) - Av. Joaquim Nabuco, 1950, Centro. Manaus - AM.

Email: horminoneto@hotmail.com,juniorcabra1929@hotmail.com,worlen_gimack@hotmail.com

Received: June $12^{\text {th }}, 2017$

Accepted: September $25^{\text {th }}, 2017$

Published: September $30^{\text {th }}, 2017$

Copyright $\odot 2016$ by authors and Institute of Technology Galileo of Amazon (ITEG This work is licensed under the Creative Commons Attribution International License (CC BY 4.0).

http://creativecommons.org/licenses/by/4.0/ (c) (1) (3) Open Actes:

\section{ABSTRACT}

Nowadays, companies are increasingly looking to improve their production processes, qualifying their employees, offering adequate training to carry out industrial operations. Improvement of working method is part of the daily life in a factory, which produces goods or services. It is through continuous improvement that organizations seek to achieve their goals and targets set within a specific schedule. The ergonomic analysis is responsible for indicating the performance standards of .the employee in a particular work, determining the risks of the activity, the posture adopted in the accomplishment of the activity and its biomechanical movements. This study is an ergonomic analysis done in a job in a company of the industrial pole of Manaus, which in turn works in the electroplating business and is responsible for bathing in metal parts. The work has been done in one sector of the company and the name of the process is black powder box lock painting of electric gate. Through photos and videos of the process, it was possible to identify the main biomechanical movements performed by the collaborator. Environmental data were measured and classified as adequate or inadequate. After performing the simple ergonomic analysis without tools, there was a need to suggest improvements for the work station analyzed.

Keywords: Ergonomic analysis, productive processes, biomechanical movements.

\section{RESUMO}

Nos dias atuais, as empresas buscam cada vez mais aperfeiçoar seus processos produtivos, qualificando seus colaboradores, oferecendo treinamento adequado para a realização das operações industriais. Melhoria de método de trabalho faz parte do cotidiano de uma fábrica, que produz bens ou serviços. É através da melhoria contínua, que as organizações buscam alcançar seus objetivos e metas estabelecidas dentro de um cronograma específico. A análise ergonômica é responsável por indicar os padrões de desempenho do colaborador em um determinado posto de trabalho, determinando os riscos da atividade, a postura adotada na realização da atividade e seus movimentos biomecânicos. Este estudo trata-se de uma análise ergonômica feita em um posto de trabalho em uma determinada empresa do polo industrial de Manaus, que por sua vez, trabalha no ramo de galvanoplastia e é responsável pelo banho em peças de metal. O trabalho foi feito em um setor da empresa e o nome do processo é pintura a pó de caixa preta de trava de portão elétrico. Através de fotos e vídeos do processo, foi possível identificar os principais movimentos biomecânicos realizados pelo colaborador. Os dados ambientais foram mensurados e classificados como adequado ou inadequado. Após realizada a análise ergonômica simples sem aplicação de ferramentas, houve a necessidade de sugestão de melhorias para o posto de trabalho analisado.

Palavras Chaves: Análise ergonômica, processos produtivos, movimentos biomecânicos. 


\section{INTRODUÇÃO}

Em geral a maioria das empresas utilizam de processos produtivos ou administrativos que exijam um certo esforço do colaborador. Esses movimentos de trabalho realizados de forma inadequada podem gerar uma série de consequências negativas ao trabalhador e a empresa. Por exemplo, um trabalhador pode sofrer um acidente de trabalho ou pode desenvolver uma doença relacionada ao trabalho, tendo como causa principal, o esforço repetitivo e a forma inadequada de realizar a atividade.

Hoje em dia, muitos trabalhadores estão desenvolvendo doenças relacionadas ao trabalho, e ficam um período afastado da empresa, gerando um custo bastante significativo, pois é uma mão de obra que está sendo paga e não está sendo utilizada.

Uma análise ergonômica pode trazer informações muito importantes para um gestor de uma empresa, uma vez que, com a realização de uma avaliação, a empresa pode tomar ações preventivas e evitar uma série de custos desnecessários que em alguns casos, pode levar a empresa à beira da falência dependendo de como a empresa afetou de forma negativa as funções do trabalhador, às vezes impossibilitando-o de atuar em algumas áreas, fazendo com que o mesmo tenha limitações em realizar outras atividades, por decorrência do trabalho realizado de forma errada.

No caso, a empresa, pode ser multada e sofrer processos judiciais movidos pelo funcionário. Uma forma simples de prevenção a essas consequências, começa a partir de uma avaliação ergonômica dos postos de trabalho, coletando informações dos colaboradores sobre seus métodos e possíveis sugestões de melhoria, para que facilite o processo e não cause desconforto ao realizar uma certa tarefa.

Os postos de trabalho tem que estar de acordo com as normas regulamentadoras de Higiene e Segurança do Trabalho e Ergonomia. São as chamadas NR's.

Este estudo trata-se de uma pesquisa feita em um posto de trabalho em uma empresa de galvanoplastia do Polo Industrial de Manaus e avalia o método de trabalho realizado em um processo de pintura a pó, tendo também os dados da produção, os riscos recorrentes e os possíveis impactos gerados à saúde do trabalhador.

\section{REVISÃO BIBLIOGRÁFICA}

\section{II.1 HISTÓRICO DA ERGONOMIA}

Historicamente o projeto do posto de trabalho surgiu antes da Ergonomia, ou seja, surgiu com o trabalho, e este, como sabemos, é tão antigo quanto a humanidade.

A Ergonomia como ciência teve suas origens em estudos e pesquisas na área da Fisiologia do Trabalho, mais especificamente na fadiga e no consumo energético provocado pelo trabalho. Os efeitos da ergonomia sempre acompanharam o homem em suas atividades, tornando-as mais leves e mais eficientes. Porém, somente se afirmou como ciência em meados do século XX.

Em 12 de julho de 1949, um grupo de cientistas e pesquisadores se reuniu na Inglaterra, para discutir e formalizar a existência de uma nova área de aplicação interdisciplinar da ciência [1]. As primeiras medidas e observações sistemáticas do trabalho foram desenvolvidas por engenheiros, organizadores do trabalho, pesquisadores e médicos, sendo que os engenheiros e organizadores o fazem numa perspectiva de aperfeiçoamento do rendimento do homem no trabalho [2].

\section{II.2 DEFINIÇÕES DE ERGONOMIA}

A palavra Ergonomia deriva do grego Ergon [trabalho] e nomos (normas, regras, leis). Trata-se de uma disciplina orientada para uma abordagem sistêmica de todos os aspectos da atividade humana. De acordo com [3], a Ergonomia é o estudo científico da relação entre o homem e seu ambiente de trabalho. Nesse sentido, o termo "ambiente" abrange não apenas o meio propriamente dito em que o homem trabalha, mas também os instrumentos, as matérias-primas, os métodos e a organização desse trabalho. Relacionada a tudo isso está a natureza do próprio indivíduo, que inclui suas habilidades, capacidades e limitações.

\section{II.3 OBJETIVOS DA ERGONOMIA}

A ergonomia estuda vários aspectos: a postura e os movimentos corporais (sentados, em pé, empurrando, puxando e levantando cargas), fatores ambientais (ruídos, vibrações, iluminação, clima, agentes químicos), informação (informações captadas pela visão, audição e outros sentidos), relações entre mostradores e controles, bem como cargos e tarefas (tarefas adequadas, interessantes).

A conjugação adequada desses fatores permite projetar ambientes seguros, saudáveis, confortáveis e eficientes, tanto no trabalho quanto na vida cotidiana. A ergonomia baseia-se em conhecimentos de outras áreas científicas, como a antropometria, biomecânica, fisiologia, psicologia, toxicologia, engenharia mecânica, desenho industrial, eletrônica, informática e gerência industrial. Ela reuniu, selecionou e integrou os conhecimentos relevantes dessas áreas, para desenvolver métodos e técnicas específicas para aplicação desses conhecimentos na melhoria do trabalho e das condições de vida, tanto dos trabalhadores, como da população em geral [4].

No ambiente de trabalho, a ergonomia é essencial para a produtividade e qualidade, uma vez que a aplicação desses conhecimentos científicos em diversas áreas auxiliam na construção de métodos de trabalho eficientes sem risco à saúde do trabalhador, bem como evita possíveis acidentes. Em relação aos seus objetivos, a ergonomia busca a segurança, satisfação e o bem-estar dos trabalhadores no seu relacionamento com sistemas produtivos [1].

\section{II.4 BIOMECÂNICA}

A Biomecânica é a disciplina da ergonomia dedicada ao estudo do corpo humano, das forças que atuam no corpo, considerando este como uma estrutura que funciona segundo as leis da mecânica. O corpo humano é considerado um equipamento, que produz movimentos rápidos e precisos, transforma alimentos variados em energia, possui capacidade de adaptação, e além de tudo se regenera quando avariado, porém, para efeito de estudo, pode ser visto como uma máquina, formado por uma estrutura rígida, com articulações e com sistemas tracionadores [4].

De acordo com [5], as forças aplicadas ao corpo podem ser divididas em dois tipos, as forças externas e as forças internas, onde, as forças externas são aquelas exercidas na superfície do corpo e as forças internas são geradas pelos músculos e tendões e são reação às externas.

Segundo [6], a biomecânica ocupacional preocupa-se com os movimentos corporais e forças relacionadas ao trabalho, preocupa-se com as interações físicas do trabalhador, com o seu posto de trabalho, máquinas, ferramentas e materiais, visando reduzir os riscos de distúrbios músculos esqueléticos, analisando basicamente a questão das posturas corporais no trabalho, a 
aplicação de forças, bem como as suas consequências aos trabalhadores.

\section{II.5 ASPECTOS AMBIENTAIS}

\section{II.5.1 TEMPERATURA}

Do ponto de vista térmico, a medida em que o meio se torna hostil, maiores serão as exigências de termorregulação. $\mathrm{O}$ trabalhador, instintivamente, procura melhorar seu conforto, o que pode afetar sua atenção durante a atividade específica que está realizando e favorecer, assim, a distração e as consequentes perdas de eficiência e segurança no trabalho [7].

Conforto térmico, segundo [8], relaciona seis variáveis principais: a atividade, a vestimenta, a temperatura média radiante, a temperatura, a velocidade e a umidade do ar. A temperatura é um indício do fluxo de calor que exprime o grau de calor ou frio num lugar ou num corpo, cujas sensações produzidas no corpo humano são dependentes do grau de umidade do ar ambiente e da velocidade do vento [9].

Conforme [10], a temperatura é um ponto que deve merecer o maior cuidado quando se busca criar condições ambientais de trabalho adequadas; há temperaturas que oferecem sensação de conforto, enquanto outras promovem sensações desagradáveis e até prejudiciais à saúde. Ainda segundo o autor, em ambientes de temperatura elevada ocorre redução na velocidade das reações e diminuição da agilidade mental, o que aumenta a possibilidade de acidentes, além de afetar significativamente o rendimento.

\section{II.5.2 LUMINOSIDADE}

Conforto visual, segundo [11], é entendido como a existência de um conjunto de condições em determinado ambiente, no qual o ser humano pode desenvolver suas tarefas visuais com o máximo de acuidade (medida da habilidade do olho humano em discernir detalhes) e precisão visual. A claridade do ambiente de trabalho é determinada não apenas pela intensidade da luz mas, também, pelas distâncias e pelo índice de reflexão das paredes, teto, piso, máquinas e mobiliário.

Um bom sistema de iluminação, com uso adequado de cores e a criação de contrastes, pode produzir um ambiente agradável, onde as pessoas trabalhem confortavelmente, com pouca fadiga, monotonia e acidentes, produzindo com maior satisfação [12]. Quando a luz emitida por uma fonte atinge uma superfície, esta será iluminada; assim, iluminância (E), é a medida da quantidade de luz incidente numa superfície por unidade de área; sua unidade é lúmen m-2 ou lux (lx) [13].

\section{II.5.3 RUÍDO}

A presença de ruídos, os chamados barulhos, no ambiente de trabalho pode perturbar e, com o tempo a exposição pode provocar a surdez ocupacional. Os sintomas iniciais apresentados nos trabalhadores é a dificuldade de entender e falar nestes ambientes ruidosos. O ruído é um fenômeno físico que, no caso da acústica, indica uma mistura de sons cujas frequências não seguem nenhuma lei precisa. De acordo com [4], o ruído provoca interferência nas comunicações e redução da concentração que podem ocorrer até com ruídos considerados baixos, geralmente apresenta consequências de distúrbios gastrintestinais, irritabilidade, vertigens, nervosismo, aceleração do pulso, aumento da pressão arterial, contração dos vasos sanguíneos e músculos, surdez.

As perturbações nas comunicações e no trabalho intelectual ocorrem a partir dos $80 \mathrm{~dB}$ (A) de ruído, isso pode acontecer até mesmo nos níveis de ruído que não provocam surdez, pois geralmente estes ruídos são provocados por máquinas, equipamentos e pessoas [4].

A tabela 1 apresenta recomendações sobre os limites máximos de ruídos permitidos para cada tipo de atividade.

Tabela 1: Limites máximos de ruídos que não provocam perturbações nas atividades.

\begin{tabular}{c|c}
\hline Tipo de atividade & $\mathrm{dB}(\mathrm{A})$ \\
\hline Trabalho físico pouco qualificado & 80 \\
\hline Trabalho físico qualificado & 75 \\
\hline Trabalho físico de precisão & 70 \\
\hline Trabalho rotineiro de escritório & 70 \\
\hline Trabalho de alta precisão & 60 \\
\hline Trabalho em escritórios com conversas & 60 \\
\hline Concentração mental moderada & 55 \\
\hline Grande concentração mental (projeto) & 45 \\
\hline Grande concentração mental (leitura) & 35 \\
\hline
\end{tabular}

Fonte: [4].

\section{II.6 NR 17}

No Brasil a Norma Regulamentadora de segurança do trabalho em ergonomia é a NR17. Segue abaixo alguns itens da norma sobre as condições ambientais de trabalho conforme [14]. 17.5. Condições ambientais de trabalho.

17.5.1. As condições ambientais de trabalho devem estar adequadas às características psicofisiológicas dos trabalhadores $\mathrm{e}$ à natureza do trabalho a ser executado.

17.5.2. Nos locais de trabalho onde são executadas atividades que exijam solicitação intelectual e atenção constantes, tais como: salas de controle, laboratórios, escritórios, salas de desenvolvimento ou análise de projetos, dentre outros, são recomendadas as seguintes condições de conforto:

a) níveis de ruído de acordo com o estabelecido na NBR 10152, norma brasileira registrada no INMETRO;

b) índice de temperatura efetiva entre $20 \mathrm{oC}$ (vinte) e $23 \mathrm{oC}$ (vinte e três graus centígrados);

c) velocidade do ar não superior a $0,75 \mathrm{~m} / \mathrm{s}$;

d) umidade relativa do ar não inferior a 40 (quarenta) por cento.

17.5.2.1. Para as atividades que possuam as características definidas no subitem 17.5.2, mas não apresentam equivalência ou correlação com aquelas relacionadas na NBR 10152, o nível de ruído aceitável para efeito de conforto será de até $65 \mathrm{~dB}(\mathrm{~A})$ e a curva de avaliação de ruído (NC) de valor não superior a $60 \mathrm{~dB}$.

17.5.2.2. Os parâmetros previstos no subitem 17.5.2 devem ser medidos nos postos de trabalho, sendo os níveis de ruído determinados próximos à zona auditiva e as demais variáveis na altura do tórax do trabalhador.

17.5.3. Em todos os locais de trabalho deve haver iluminação adequada, natural ou artificial, geral ou suplementar, apropriada à natureza da atividade.

17.5.3.1. A iluminação geral deve ser uniformemente distribuída e difusa.

17.5.3.2. A iluminação geral ou suplementar deve ser projetada e instalada de forma a evitar ofuscamento, reflexos incômodos, sombras e contrastes excessivos.

17.5.3.3. Os níveis mínimos de iluminamento a serem observados nos locais de trabalho são os valores de iluminâncias estabelecidos na NBR 5413, norma brasileira registrada no INMETRO. 
17.5.3.4. A medição dos níveis de iluminamento previstos no subitem 17.5.3.3 deve ser feita no campo de trabalho onde se realiza a tarefa visual, utilizando-se de luxímetro com fotocélula corrigida para a sensibilidade do olho humano e em função do ângulo de incidência.

17.5.3.5. Quando não puder ser definido o campo de trabalho previsto no subitem 17.5.3.4, este será um plano horizontal a $0,75 \mathrm{~m}$ (setenta e cinco centímetros) do piso.

\section{MATERIAIS E MÉTODOS}

A classificação desta pesquisa é definida como pesquisa aplicada. Em relação à forma de abordagem é definida como quantitativa e qualitativa, pois incluem dados numéricos e informações não numéricas para análise do problema. A classificação quanto aos fins é: Descritiva e Exploratória. Em relação aos meios é classificada como um estudo de caso.

\section{III.1 POPULAÇÃO DA PESQUISA.}

$\checkmark 60$ funcionários entre seus operadores, supervisores e gerentes em todos os setores da fábrica.

$\checkmark \quad 10$ tipos de serviços diferentes oferecidos pela empresa.

$\checkmark 20$ postos de trabalho relacionando todos os serviços.

\section{III.2 AMOSTRA DA POPULAÇÃO}

$\checkmark 1$ colaborador

$\checkmark \quad 1$ posto de trabalho

\section{3 COLETA DE DADOS}

Foi realizada a coleta de dados da produção da empresa. Os dados apresentam fotos e vídeos do processo de tintura a pó. Foi descrita também a organização do trabalho, incluindo o tempo de trabalho efetivo, produção horária, ciclo de trabalho, produção por minuto, taxa de ocupação e taxa de repouso em relação à atividade realizada pelo colaborador em seu posto de trabalho e suas respectivas descrições biomecânicas dos movimentos realizados e situações inadequadas observadas no processo e no setor.

\section{III.4 RECURSOS UTILIZADOS}

Para a pesquisa foram utilizados os seguintes recursos:

\footnotetext{
$\checkmark$ Celular;

$\checkmark$ Prancheta;

$\checkmark$ Calculadora;

$\checkmark$ Termômetro;

$\checkmark$ Decibelímetro

$\checkmark$ Luxímetro
}

\section{IV.RESULTADOS E DISCUSSÕES}

\section{IV.1 DESCRIÇÃO DO PROCESSO DE PINTURA}

O operador realiza a atividade cíclica. O processo é realizado em um tempo de 1 minuto e 18 segundos, ou seja, 78 segundos, porém cada ciclo é feita a pintura de 10 caixas pretas de trava de portão elétrico. Com isso temos um Tempo de ciclo de 7,8 segundos por peça. Há um equipamento que controla a quantidade de tinta à pintura a pó.

\section{IV.2 EQUIPAMENTO DE CONTROLE DE TINTA}

Para um controle da quantidade de tinta na peça (caixa preta de portão elétrico) o equipamento abaixo realiza esse controle e é injetada somente a quantidade suficiente para a pintura conforme a figura 1 abaixo.

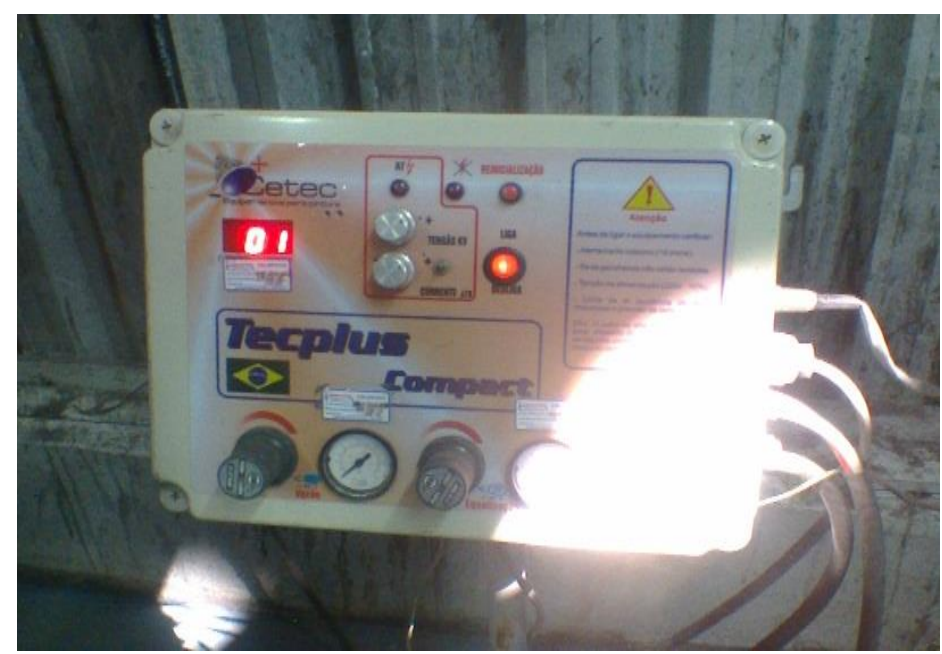

Figura 1: Equipamento de Controle de tinta.

Fonte: Autores, (2017).

\section{IV.3 TABELA DE JORNADA DE TRABALHO}

Segue abaixo na tabela 2 a jornada de trabalho durante um turno na empresa.

Tabela 2: Jornada de Trabalho.

\begin{tabular}{|c|c|c|c|}
\hline $\begin{array}{c}\text { JORNADA } \\
\text { DE }\end{array}$ & $\begin{array}{c}\text { ENTRADA } \\
\text { TRABALHO }\end{array}$ & $\begin{array}{c}\text { SAÍDA } \\
\mathbf{1 7 : 0 0}\end{array}$ & $\begin{array}{c}\text { TOTAL } \\
\text { 10 HORAS }\end{array}$ \\
\hline PAUSA DE & INICIO & FIM & 10 MINUTOS \\
MANHÃ & $09: 00$ & $09: 10$ & \\
\hline ALMOÇO & INÍCIO & FIM & \multirow{2}{*}{60 MINUTOS } \\
\hline PAUSA DE & $12: 00$ & $13: 00$ & \\
TAIÍCIO & FIM & 10 MINUTOS \\
\hline
\end{tabular}

Fonte: Autores, (2017).

\section{IV.4 ORGANIZAÇÃO DO TRABALHO}

Foi coletado alguns dados do posto de trabalho e depois foi montada a tabela de organização do trabalho conforme a tabela 3 .

Tabela 3: Organização do Trabalho.

\begin{tabular}{lll}
\hline Tempo de trabalho efetivo & 8.67 & Horas \\
\hline Produção por turno & 2000 & Peças \\
\hline Produção horária & 230.68 & Peças/horas \\
\hline Produção por minuto & 3.84 & Peças/minuto \\
\hline Ciclo de trabalho & 15.626 & Peças/segundo \\
\hline Ciclo de trabalho real & 7.8 & Segundos/peça \\
\hline Taxa de ocupação & 0,4992 & $49,92 \%$ \\
\hline Taxa de repouso & 0,5008 & $50,08 \%$ \\
\hline
\end{tabular}

Fonte: Autores, (2017). 


\section{IV.5 FOTOS DO POSTO DE TRABALHO}

Para uma abordagem ergonômica do posto de trabalho, se fez necessário tirar fotos dos movimentos biomecânicos do colaborador. A Figura 2 mostra o colaborador realizando o movimento de extensão de braço e ombro para encaixar a gancheira com as peças.

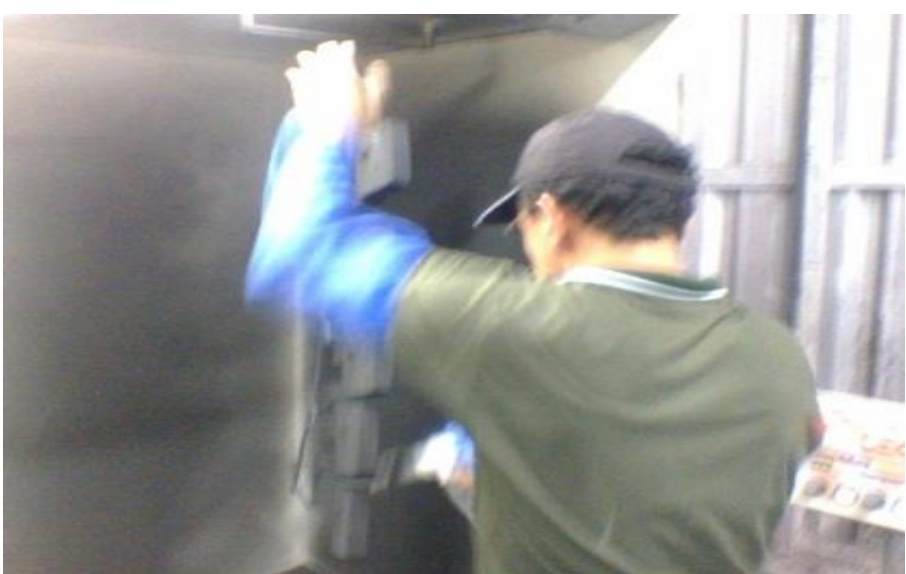

Figura 2: Extensão de braço e ombro.

Fonte: Autores, (2017).

A figura 3 mostra o colaborador realizando uma rotação de tronco. Ele faz esse movimento para pintar do lado as caixas de portão elétrico.

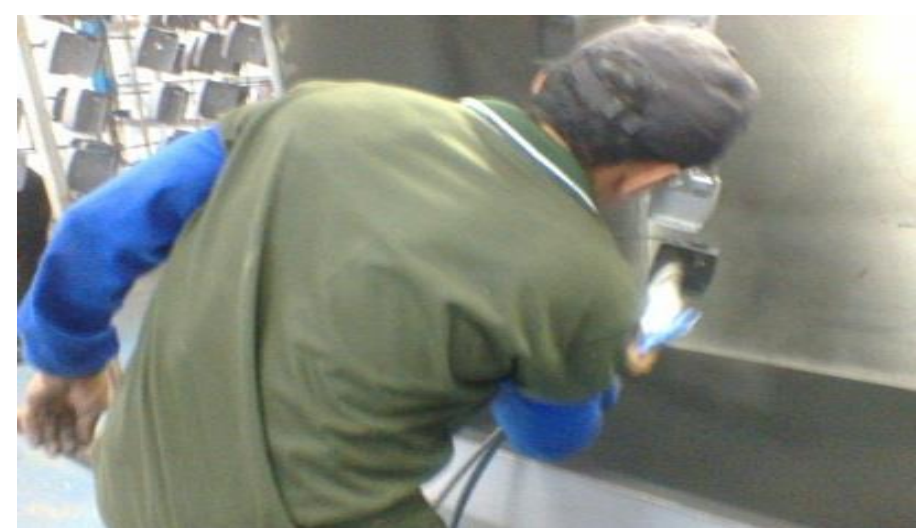

Figura 3: Rotação de tronco.

Fonte: Autores, (2017).

Na figura 4 o colaborador faz o movimento de rotação lateral do pescoço para pintar a frente da peça.

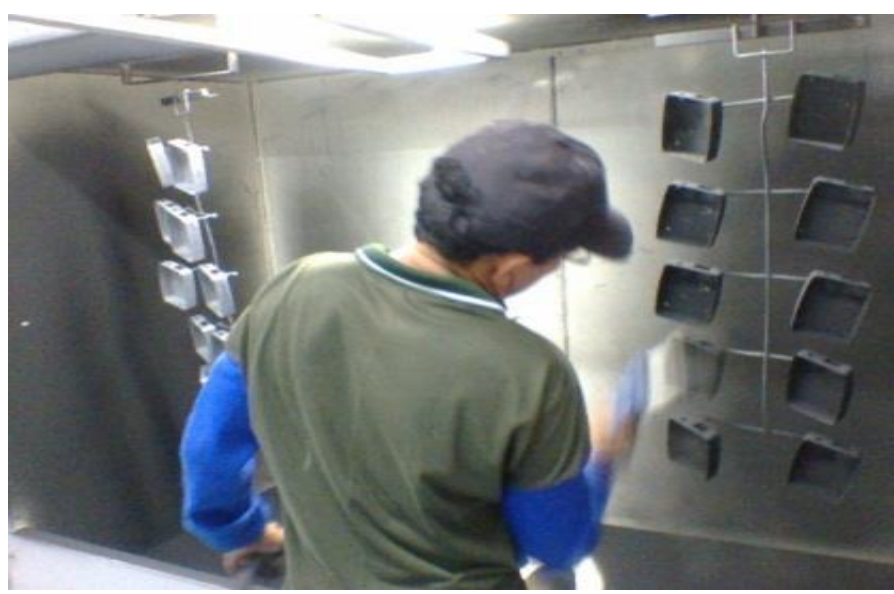

Figura 4: Rotação lateral de pescoço.

Fonte: Autores, (2017).
$\mathrm{Na}$ figura 5, para pintar as peças que estão na parte de cima da cabine, o colaborador realiza o movimento de flexão de braço externo.

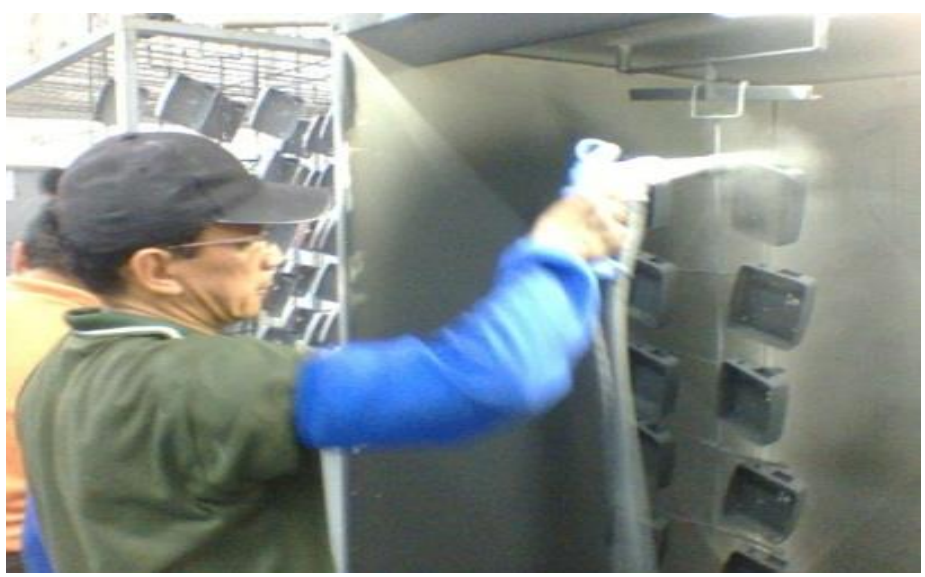

Figura 5: Flexão de Braço externo.

Fonte: Autores, (2017).

A figura 6 mostra o colaborador retirando a gancheira com as peças, realizando o movimento biomecânico de elevação de braço. Ele faz a pintura de cada caixa em 7,8 segundos, e armazena ao lado da cabine para a secagem. Cada gancheira tem a capacidade de armazenamento de 10 caixas pretas de portão elétrico.

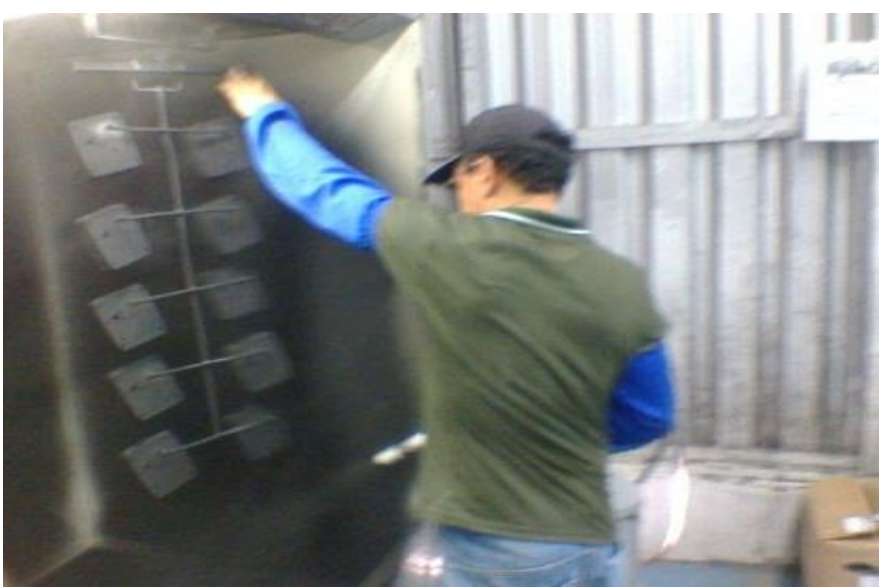

Figura 6: Elevação de Braço.

Fonte: Autores, (2017).

A figura 7 mostra o movimento biomecânico realizado para pintar a parte de baixo das caixas, ele faz uma preensão palmar seguido de uma flexão da servical.

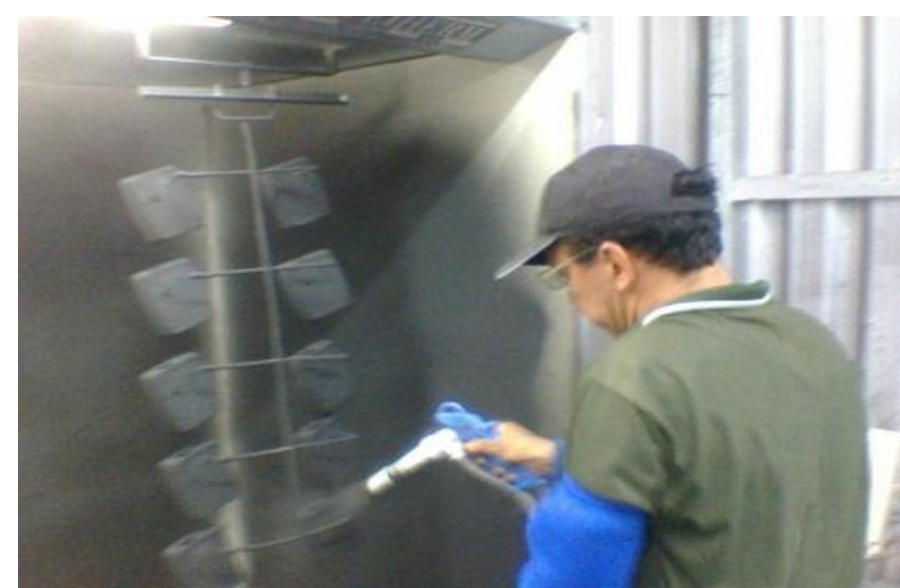

Figura 7: Preensão palmar e flexão da servical.

Fonte: Autores, (2017). 


\section{IV.6 DADOS AMBIENTAIS}

Foram medidos 3 principais dados ambientais do setor de pintura a pó da empresa. Os resultados encontrados se encontram abaixo conforme a tabela 4 .

Tabela 4: Dados Ambientais do Setor de Pintura.

\begin{tabular}{|l|l|l|l|}
\hline \multicolumn{1}{c|}{$\begin{array}{c}\text { Condições } \\
\text { Ambientais }\end{array}$} & \multicolumn{1}{|c|}{ Referência } & $\begin{array}{c}\text { Valor } \\
\text { Medido }\end{array}$ & Situação \\
\hline Iluminamento & $\begin{array}{l}\text { NR 17-17.5.2 - } \\
\text { NBR 8995-1:2013 } \\
\text { A partir de 300 Lux }\end{array}$ & Lux & Adequado \\
\hline Ruído & $\begin{array}{l}\text { NR17 - 17.5.2 } \\
\text { Até 85 dB(A) }\end{array}$ & $\begin{array}{l}90 \\
\mathrm{~dB}(\mathrm{~A})\end{array}$ & Inadequado \\
\hline Temperatura & $\begin{array}{l}\text { NR 15 - Anexo 3 } \\
\text { Trabalho moderado } \\
\text { Até 26,7 } 7^{\circ} \mathrm{C}\end{array}$ & $32^{\circ} \mathrm{C}$ & Inadequado \\
& & \\
\hline
\end{tabular}

Fonte: Autores, (2017).

\section{IV.7 SITUAÇÕES INADEQUADAS}

$\checkmark$ Ambiente de trabalho com temperatura acima de 24 graus Celsius. Temperatura entre 30 e 35 graus;

$\checkmark \quad$ A falta do uso de luvas para a atividade;

$\checkmark$ A falta de EPI's auricular, pois o ambiente produz bastante ruído;

$\checkmark \quad$ Falta de uma máscara para a realização da atividade;

$\checkmark \quad$ Altura do suporte para as peças elevada.

\section{IV.8 SUGESTÕES DE MELHORIA}

$\checkmark \quad 1$ - utilizar equipamento de proteção individual (EPI). Protetor Auricular.

$\checkmark \quad$ 2-Colocar o suporte de forma vertical para horizontal para que o colaborador não faça movimentos de agachamento e rotação de tronco.

$\checkmark \quad$ 3- Realizar ginástica laboral (2 vezes por turno)

$\checkmark \quad$ 4- Colocar o suporte em uma altura mais baixa para que a atividade seja realizada para que o braço não ultrapasse o ângulo de 90 graus.

\section{CONCLUSÃO}

Após a realização de fotos do processo de pintura a pó da empresa estudada, conclui-se que o colaborador realiza diversos movimentos biomecânicos durante um ciclo de trabalho. Tais movimentos repetitivos durante uma jornada de trabalho podem causar desconfortos no colaborador ao final do dia. No caso do posto de pintura a taxa de ocupação é de $49,92 \%$, ou seja, o operador do posto consegue atingir a meta de produção muito antes do final do turno e o mesmo é designado para outras atividades ou a pintura de outros tipos de peças no mesmo local de trabalho. As condições ambientais do setor de pintura foram mensuradas e os valores dos nível de ruído e temperatura estão acima dos limites de tolerância de acordo com a NR 17.5, exigindo do colaborador o uso de EPI's. Em relação ao conforto do posto de trabalho, o mesmo é considerado inadequado, porém podem ser feitas melhorias para torna-lo adequado. De acordo com a observação do processo e o nível de repetição dos movimentos biomecânicos realizados pelo colaborador, pode-se afirmar que o risco ergonômico em relação à atividade é considerado baixo, visto que o funcionário realiza outras tarefas dentro da empresa

\section{REFERÊNCIAS}

[1] Iida, Itiro. Ergonomia, projeto e produção. São Paulo: Edgard Blucher LTDA, 2002.

[2] Laville, A. Ergonomia. Trad.: Márcia Maria Neves Teixeira. São Paulo: Edusp, 1977.

[3] Palmer, Colin. Ergonomia. Rio de Janeiro: Fundação Getúlio Vargas, 1976.

[4] Dul, J., Weerdmeester, B. Ergonomia Prática. Tradução de Itiro Iida. 2. ed. São Paulo. Edgard Blücher, 2004.

[5] Moro, A. R. P. Análise Biomecânica da Postura Sentada: Uma Abordagem Ergonômica do Mobiliário Escolar. 2000. Tese (Doutorado em Educação Física) UFSM, Universidade Federal de Santa Maria, Santa Maria.

[6] Iida, I. Ergonomia: Projeto e Produção. São Paulo: editora Edgard Blucher, 2005.

[7] Couto, H. A. Ergonomia aplicada ao trabalho - O manual técnico da máquina humana. Belo Horizonte: Ergo Editora, 1995, $353 \mathrm{p}$.

[8] Rivero, R. Acondicionamento térmico natural Arquitetura e clima. Porto Alegre: DCL, 1986. 240p.

[9] Minetti, L. J.; Souza, A. P.; Machado, C. C.; Baêta, F. C.; Fiedler, N. C. Análise da influência de fatores climáticos no corte florestal com motosserra. Revista Árvore, Viçosa, v.22, n.4, p.527-534, 1998.

[10] Verdussen, R. Ergonomia: a racionalização humanizada do trabalho. Rio de Janeiro: Livros Técnicos e Científicos, 1978. $161 \mathrm{p}$.

[11] Lamberts, R.; Philippi, P. C.; Mendes, N. Estudo do comportamento higrotérmico de material de construção: desenvolvimento de modelos para um código genérico de transferência de calor. Florianópolis: UFSC, 1997. 189p. Tese Doutorado.

[12] Iida, I. Ergonomia; projeto e produção. São Paulo: Edgard Blucher, 1990. 465p.

[13] Santos, N. Ergonomia e segurança industrial. http://www.eps.ufsc.br/ ergon/disciplinas/EPS5225. 22 agosto 2002.

[14] Norma Regulamentadora NR 17 Ergonomia Disponível em: http://www.guiatrabalhista.com.br/legislacao/nr/nr17.htm 